\title{
The pedagogical efficacy of ESP courses for Iranian students of engineering from students' and instructors' perspectives
}

\author{
Sartoon Mostafavi ${ }^{1}$, Ahmad Mohseni ${ }^{2^{*}}$ and Gholam-Reza Abbasian ${ }^{3}$
}

\footnotetext{
*Correspondence: amohseny1328@ gmail.com

${ }^{2}$ Associate Professor of Applied Linguistics, English Department, Faculty of Persian Literature and Foreign Languages, Islamic Azad University, South Tehran Branch, Tehran, Iran

Full list of author information is available at the end of the article
}

\begin{abstract}
Casting light on the pros and cons of every educational program, the outcomes of an effective evaluative endeavor may serve as a guideline for education authorities interested in content enhancement schemes. Focusing on English for specific purposes (ESP) courses for engineering students, the current study sought to evaluate the efficacy of technical English pedagogy in the academic context of Iran. Employing a mixed evaluative framework, the study explored the courses' effectiveness delving into the attitudes of ESP instructors and engineering students toward three major domains including needs satisfaction, content authenticity, and learner autonomy. As its secondary aim, the study examined whether there was any significant difference between students and instructors in terms of their attitudes to the courses under investigation. To accomplish the objectives, a researcher-made questionnaire was administered to 796 engineering students and 54 ESP instructors chosen from 20 randomly-selected Iranian universities. A descriptive analysis of the survey data revealed an overall disagreement with the satisfaction of some learner needs such as those related to the learning objectives, productive competences, monitoring system, and educational facilities. Additionally, the two groups of participants had significantly different perceptions of the authenticity of the instructional content as well as the satisfaction of the target needs. The findings may help local authorities adapt the existing ESP pedagogy in Iran to suit the genuine needs of students.
\end{abstract}

Keywords: ESP, Language pedagogy, Course evaluation, Technical English

\section{Introduction}

Given that unrestricted access to discipline-specific information is fast becoming a necessity in the global village we are used to today, an acceptable level of technical language knowledge seems to be indispensable to millennial undergraduate students. Accordingly, tertiary education not only is supposed to foster the development of different fields of knowledge but also should enable learners to communicate across the international community of every discipline. This could explain why a great deal of importance has been attached to technical English teaching by the authorities in charge of undergraduate curriculum design worldwide.

(c) The Author(s). 2021 Open Access This article is licensed under a Creative Commons Attribution 4.0 International License, which permits use, sharing, adaptation, distribution and reproduction in any medium or format, as long as you give appropriate credit to the original author(s) and the source, provide a link to the Creative Commons licence, and indicate if changes were made. The images or other third party material in this article are included in the article's Creative Commons licence, unless indicated otherwise in a credit line to the material. If material is not included in the article's Creative Commons licence and your intended use is not permitted by statutory regulation or exceeds the permitted use, you will need to obtain permission directly from the copyright holder. To view a copy of this licence, visit http://creativecommons.org/licenses/by/4.0/. 
To follow such a general trend, the practice of technical language teaching has been included in the Iranian undergraduate curriculum in the form of purposeful ESP programs with a domain-relevant content. Nonetheless, as evidenced empirically (e.g., Aliakbari \& Boghayeri, 2014; Khodi, 2015; Moslemi, Moinzadeh, \& Dabaghi, 2011), ESP courses held in the academic context of Iran are hardly recognized as satisfactory and motivating subject areas. The failure of Iranian ESP pedagogy to arouse the interest of students is believed to be rooted in a string of contributory factors including a) the poor proficiency of learners in general and semi-technical English (Mahdavi Zafarghandi, 2005), the inefficient and unrealistic instructional content yielded by holistic analyses of learner needs (Amirian \& Tavakoli, 2009; Atai \& Nazari, 2011; Mahdavi Zafarghandi, Khalili Sabet, \& Sharoudi Lomar, 2014), and flawed or ineffective teaching methods and techniques (Mazdayasna \& Tahririan, 2008).

\section{Theoretical background to the study}

ESP is generally characterized as a subject area with three distinguishing features: a) being concerned with English instruction intended for students with specific needs, b) dealing with the language appropriate to a particular domain-specific context or setting, and c) being designed taking account of teaching methods, materials, and activities well suited to the demands of a particular discipline (Dudley-Evans \& St. John, 1998). ESP programs, like any other educational programs, encompass various dimensions such as syllabus design, course process, materials and measurement selection/adaptation, and evaluation (Altmişdört, 2017).

Evaluation, generally defined by McNamara (2000) as the process of making a valid judgment about a particular program through gathering, analyzing, and interpreting a bewildering array of information, has always been of paramount importance to ESP course designers. Such prominence may lie in the fact that a proper and constant evaluation could guarantee the success and effectiveness of all other aspects of the program such as curriculum/syllabus design, teaching/learning processes, and learning environment (Weir \& Roberts, 1994).

The chief aim of every evaluation project is to reach a firm decision about the developmental process of a certain program (Worthen, Sanders, \& Fitzpatrick, 2004). Such decision, as asserted by Wang (2009), may yield a variety of results including a) steady progress in objectives attainment, b) improvement in program implementation, c) provision of accountability data, d) provision of community support for initiatives, e) provision of funding assurance, and f) improvement in policy makers' confidence. Having reviewed the general notions of program evaluation, Stavropoulou and Stroubouki (2014) opined that the merits of an in-depth program evaluation could profit program developers and authorities in different dimensions such as program development, curriculum design, and curriculum implementation.

As contended by Kiely and Rea-Dickins (2005), the early attempts to evaluate language programs were mainly concerned with achievement data. Nonetheless, such reputation has changed dramatically over the years and, recent models of program evaluation, particularly those targeted at language teaching/learning, are concerned with various contributory elements, aside from assessment data. The two-level evaluative model proposed by Hutchinson and Waters (1987), which entails both learner assessment and course evaluation, could be regarded as a departure from the one-dimension style of ESP evaluation. More recently, 
Watanabe, Norris, and Gonzales (2009) have proposed a comprehensive model of FL program evaluation whereby the views expressed by a group of stakeholders are analyzed focusing on three aspects of a certain program including a participatory model, professional accountability, and teacher empowerment.

Relying upon the underpinnings of the models proposed by Hutchinson and Waters (1987) and Watanabe et al. (2009), Tsou and Chen (2014) suggested an updated evaluative framework. The framework promotes program evaluation based on a four-component scheme including course evaluation, learner assessment, teacher participation, and stakeholders' concerns. The four components included in the framework are the criteria proposed either by Hutchinson and Waters (1987) or Watanabe et al. (2009).

\section{Empirical background to the study}

Although a plenitude of investigation has been carried out to explore the effectiveness of tertiary level ESP courses in the academic context of Iran (e.g., Abbasian \& Mahdavi, 2011; Iranmehr, Atai, \& Babaii, 2018; Khoshsima \& Khosravani, 2014; Mahdavi Zafarghandi et al., 2014; Malmir \& Bagheri, 2019; Mashhadi Heidar \& Abassy Delvand, 2015; Mazdayasna \& Tahririan, 2008; Mostafaei Alaei \& Ershadi, 2017; Sherkatolabbasi \& Mahdavi Zafarghandi, 2012; Zand-Moghadam, Meihami, \& Ghiasvand, 2018), the study of technical English pedagogy specific to the students of engineering seems to be still scant. Additionally, the few studied which focused on technical English for engineering students (e.g., Danaye-Tous \& Haghighi, 2014; Hatam \& Shafiei, 2012) were grounded on a fragmental view about course evaluation and, as a result, dealt only with a certain aspect of ESP courses (e.g., textbooks, language learning skills, etc.).

In an attempt to effectively investigate the real situation of technical language pedagogy in Iran, the current study sought to judge the effectiveness of ESP courses for Iranian students of engineering, delving into the attitudes expressed by two groups of stakeholders: ESP instructors and students. A statistical comparison of the two stakeholder groups' attitudes toward the courses under investigation was another area of inquiry in the current study. Pursuing the objectives enumerated above, the study sought to find clear answers to the following research questions:

1. To what extent do tertiary level ESP courses for Iranian students of engineering suit the real needs of students?

2. To what extent are tertiary level ESP courses for Iranian students of engineering capable of fostering learner autonomy?

3. How authentic are the instructional materials of tertiary level ESP courses for Iranian students of engineering?

4. Is there any significant difference between engineering students and ESP instructors in terms of their attitudes toward tertiary level ESP courses for Iranian students of engineering?

\section{Conceptual framework of the study}

The course evaluation model proposed by Tsou and Chen (2014) was employed to evaluate the courses under investigation. Course evaluation, according to this model, entails delving into three major domains including a) the fulfillment of the learner 
needs, b) the authenticity of the materials and tasks, and c) the capability of the teaching methodology to successfully foster learner autonomy. The study of the needs satisfaction based on the model is mainly grounded on Hutchinson and Waters's (1987) learning-centered approach to needs analysis, which entails exploring two distinctive sorts of needs: target situation needs and learning needs. Target needs are concerned with what learners need to effectively perform in the target situation, whereas learning needs refer to knowledge-based qualities which allow learners to experience a transition from their lacks to their wants or necessitates (Hutchinson \& Waters, 1993).

As far as the analysis of authenticity is concerned, the framework proposes three different ways including a) materials examination, b) task (activity) examination, and c) testing evaluation. Nonetheless, as contended by Tsou and Chen (2014), the evaluation of task and materials authenticity suffices for the authenticity of ESP programs. The last component of the evaluative framework is concerned with the potential of teaching methods to foster learner autonomy. Since no one-size-fits-all approach could be used to promote an autonomous ESP practice, a variety of techniques has been proposed to date. The widely-accepted techniques for fostering learner autonomy in ESP classrooms include portfolio compilation (Little, 2006; O'Leary, 2007), corpus use (Hüttner, Smit, \& Mehlmauer-Larcher, 2009), out-of-class activities (Tsou \& Chen, 2014), self-reports, and internet-aided communication with native speakers (Dobrota, 2009).

\section{Method}

\section{Participants}

Fifty four (28 male and 26 female) instructors, with an age range between 35 and 69 $(\mathrm{M}=49.3)$ and an acceptable (at least 5 years) experience of ESP teaching, participated in the current study. The instructors were chosen from 20 Iranian universities taking account of their tendency to participate in the study. Nonetheless, the universities were chosen randomly from ten distinctive geographical locations across Iran (two universities from each geographical stratum). The instructors were either English teaching (38.9\%) or discipline-specific (61.1\%) specialists. In addition to the instructor participants, a total of 796 (462 male and 334 female) undergraduate students, majoring in 12 different fields of engineering, participated in the analysis. The students ranged in age from 19 to $27(M=20.6)$ and had no experiences of either studying or living in English-speaking countries.

\section{Design}

To accomplish the purposes of the study, an exploratory design was employed and the data were gathered through a researcher-made Likert-scale questionnaire. Relying upon the evaluative framework proposed by Tsou and Chen (2014), the study explored the participants' attitudes toward the courses' capability to a) foster learner autonomy, b) provide authentic instructional content, and c) satisfy the real needs of students.

\section{Instruments}

The only instrument of the study was a 45-item researcher-made questionnaire which included three different parts: content authenticity ( 7 items), needs satisfaction (32 items), and learner autonomy (6 items). The needs satisfaction part, developed based 
on the findings of a context-relevant needs analysis by Mostafavi, S., Mohseni, A., \& Abbasian, G: A learning-centered analysis of the ESP needs of Iranian engineering students, unpublished, featured two distinctive domains to explore the satisfaction of both target situation (20 items) and learning (12 items) needs. The items representing the target needs referred to two sub-domains (i.e., learning objectives and language learning skills and sub-skills), whereas the learning needs items dealt with five sub-domains (i.e., syllabus, materials, teaching/learning features, administration, and assessment system). The content authenticity and learner autonomy items were framed taking the relevant literature into account.

Every single item of the questionnaire was rated based on a five-point Likert scale including Strongly Disagree (1), Disagree (2), Uncertain (3), Agree (4), and Strongly Agree (5). To maximize the creditability of the findings, the questionnaire was rendered into Persian before being administered to the participants. The content validity of the English version and the accuracy of the translated version were ensured relying upon the appraisal of two TEFL experts and a translation expert respectively. The questionnaire was also pilot tested in terms of reliability. To this end, the translated version was administered to 15 ESP instructors and 15 Iranian engineering undergraduates selected through convenience sampling prior to the main study. The pilot data were analyzed in terms of internal consistency and the reliability coefficients (Instructors: $\alpha=.77$, Students: $\alpha=.71$ ) were found to be acceptable.

\section{Data collection and analysis procedures}

Drawing upon the major ESP needs of engineering students and the empirical data on ESP teaching methods capable of promoting learner autonomy in ESP classrooms, the researchers devised the structured course analysis questionnaire of the study. The questionnaire was initially administered to the instructor participants through WhatsApp. They were provided with adequate time to carefully fill in the questionnaire. Owing to the broad geographical scope of the study and the large number of the student participants, the teacher participants acted as agents for the researcher and shouldered the responsibility of administering the survey to the students studying in their respective universities.

The survey data elicited from the instructor and student participants were analyzed descriptively to explore the efficacy of the ESP course in satisfying the learner needs, making use of authentic instructional content, and fostering learning autonomy. To examine whether or not the courses are perceived differently by the students and instructors, statistical package for the social sciences (SPSS, version 22) was employed and a multivariate analysis of variance (MANOVA) was run on the attitude scores estimated for each of the four domains under investigation (i.e., target needs satisfaction, learning needs satisfaction, content authenticity, and learner autonomy).

\section{Results}

\section{Results related to needs satisfaction}

To explore the extent to which ESP courses for Iranian students of engineering suit the real needs of students, the descriptive statistics of the scales provided by the students (St.) and instructors (Inst.) to express their attitudes toward the satisfaction of the target needs were estimated and displayed in Table 1. 


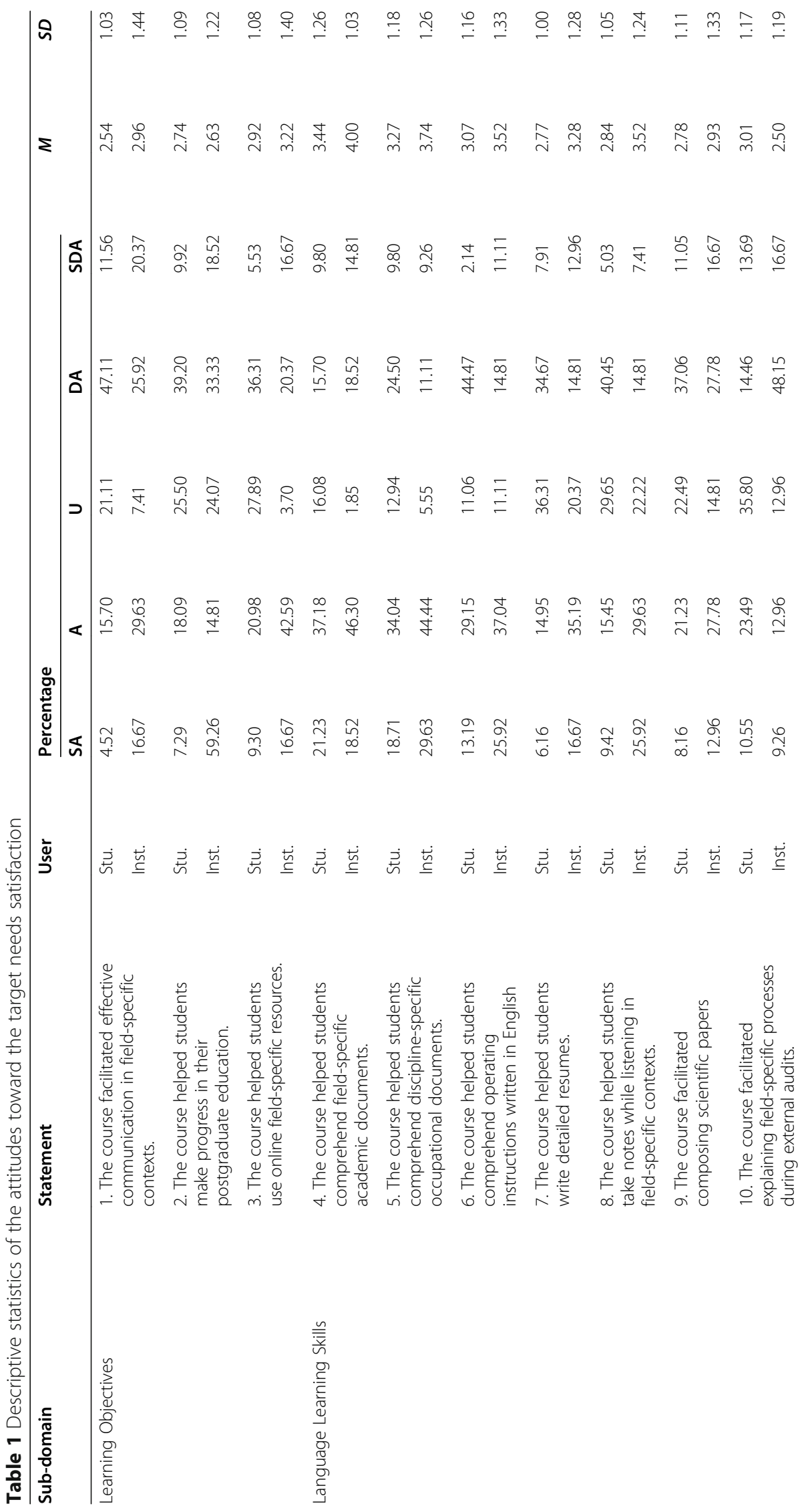




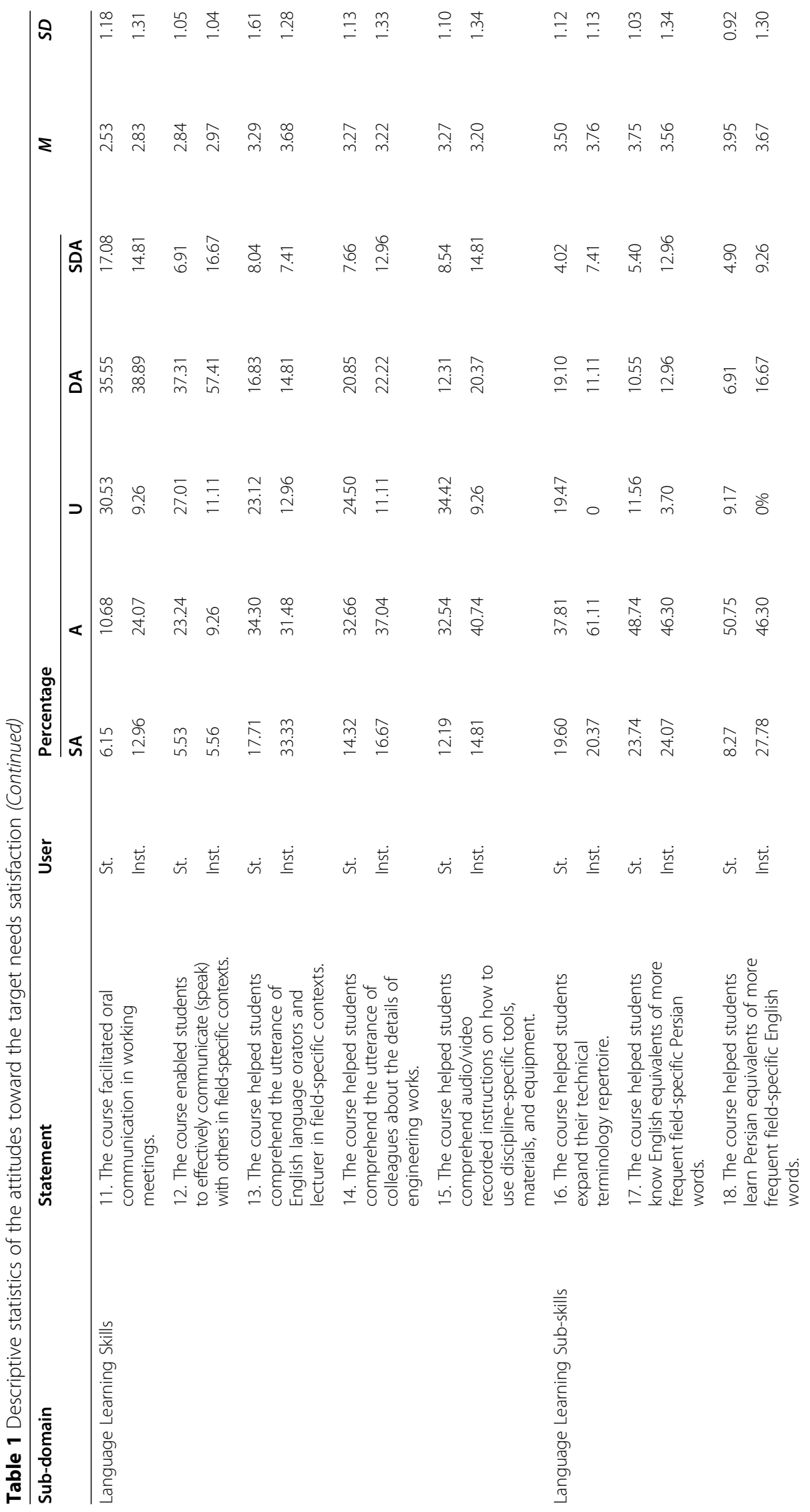




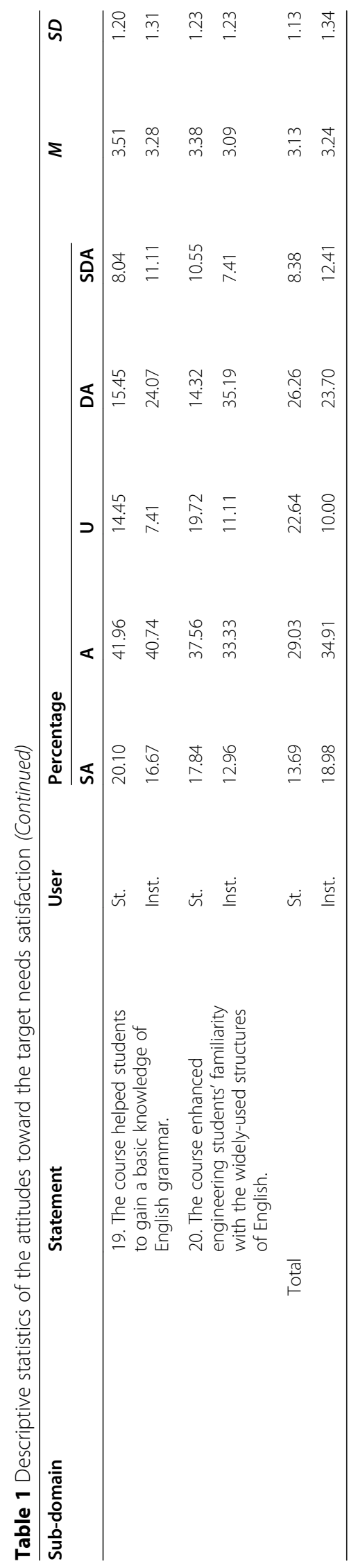


As the results presented in Table 1 demonstrate, the students had the most favorable attitude to items $18(M=3.95, S D=0.92)$ and $17(M=3.75, S D=1.03)$ reflecting the need for knowing Persian equivalents of more frequent disciplinespecific English words and vice versa. The other target situation needs that their satisfaction was approved by the majority of the student participants included items $19(M=3.51, S D=1.20), 16(M=3.50, S D=1.12), 4(M=3.44, S D=1.26), 20(M=$ 3.38, $S D=1.23), 13(M=3.29, S D=1.61), 15(M=3.27, S D=1.10), 14 \quad(M=3.27$, $S D=1.13)$, and $5(M=3.27, S D=1.18)$. These items refer to vocabulary (item 16$)$, grammar (items 19 \& 20), reading (items 4 \& 5), and listening (items 13, 14, \& 15) needs of engineering students.

On the other hand, an unsatisfactory situation was found with respect to items 11 $(M=2.53, S D=1.18)$ and $1(M=2.54, S D=1.03)$ referring to the need for oral communication in future working meetings and an effective (oral/written) communication in domain-specific contexts respectively. The descriptive statistics estimated for the remaining items testified to an overall uncertainty about the domains under investigation, simply because the percentage of the respondents either in agreement or in disagreement on them were less than $50 \%$.

According to the results in Table 1, the satisfaction of all the vocabulary (i.e., items 16, 17, \&18), listening (i.e., 13, 14, \&15) and reading (i.e., items 4, 5, 6) needs was also confirmed by the instructor participants, taking the mean and standard deviation amounts into account. Additionally, the majority of the instructors agreed on the satisfaction of the need for gaining a basic knowledge of English language grammar (item 19), making use of online discipline-specific resources (item 3), note taking while listening in discipline-specific contexts (item 8), and writing detailed resumes (item 7).

The descriptive statistics estimated based on the responses to the whole questionnaire, as presented in the last row (Total) in Table 1, showed the instructors' overall agreement on the satisfaction of the learning needs $(M=3.24, S D=1.34)$. Nonetheless, the student participants' overall attitude toward the target situation needs $(M=3.13$, $S D=1.13$ ) signified a greater proportion of the respondents who were either uncertain or disagree about the satisfaction of such needs.

Table 2 displays the item analysis results based on the participants' responses to the items referring to the learning needs of engineering students.

As displayed in Table 2, the majority of the instructor and student respondents agreed on the assessment system (Students: $M=3.80, S D=1.15$; Instructors: $M=$ 3.46, $S D=1.37$ ), task type (Students: $M=4.08, S D=1.01$; Instructors: $M=3.39$, $S D=1.43$ ), teacher expertise (Students: $M=3.72, S D=1.145$; Instructors: $M=3.93$, $S D=0.92$ ), scaffolding type (Students: $M=3.21, S D=1.133$; Instructors: $M=3.52$, $S D=1.370$ ), place of the course in the curriculum (Students: $M=3.17, S D=1.64$; Instructors: $M=3.28, S D=1.46$ ), and training hours (Students: $M=3.56, S D=$ 1.30; Instructors: $M=3.37, S D=1.49)$. The only learning need which its satisfaction was perceived differently by the two participant groups was the instructional materials (item 6). While more than half of the instructors (59.26\%) disagreed that the courses made use of both prescribed textbooks and up-to-date online resources, the majority of the student respondents (65.2\%) expressed either agreement or uncertainty in this regard. 


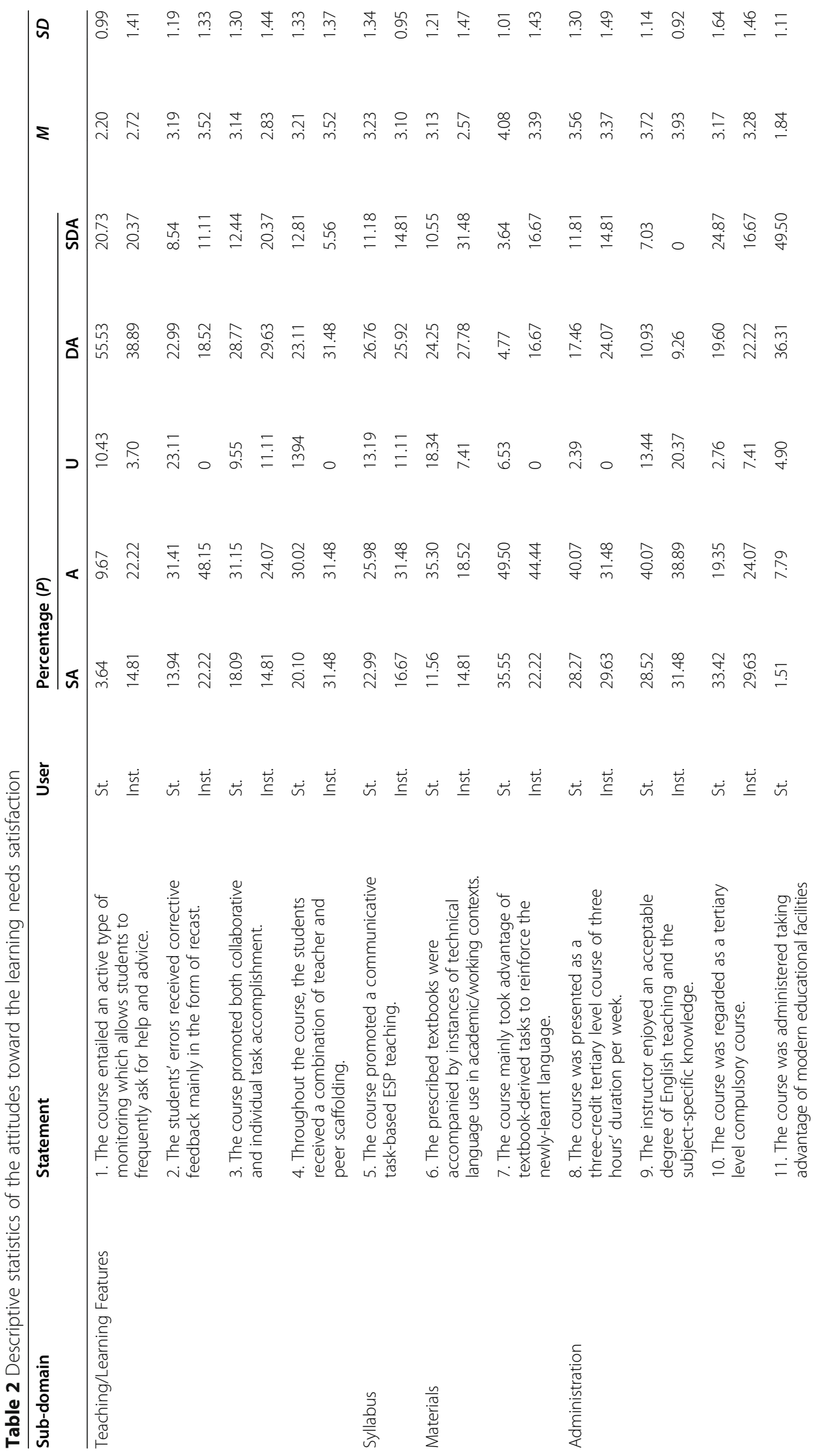




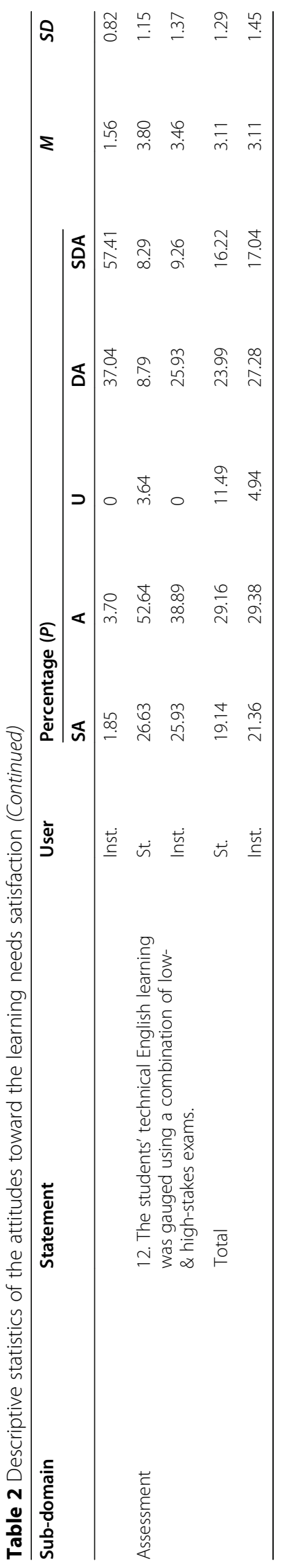




\section{Results related to content authenticity}

Table 3 depicts the distribution of the scales provided by the participants to express their attitude to the content authenticity items in the questionnaire.

As shown in Table 3, both groups of the participants agreed with the authenticity of the textbooks' reading materials/tasks (Students: $M=3.40, S D=1.20$; Instructors: $M=$ 3.31, $S D=1.21$ ) and the instructor-developed supplementary materials (Students: $M=$ 3.24, $S D=1.26$; Instructors: $M=3.20, S D=0.86$ ). Additionally, the textbooks' listening materials/tasks (item 3) were regarded as authentic by the majority of student participants. The overall attitude of the participants to the content authenticity of the courses showed a more negative attitude on the instructors' part $(M=2.80, S D=1.02)$ in comparison with the student participants $(M=3.00, S D=1.27)$.

\section{Results related to learner autonomy}

Table 4 details the participants' responses to the items referring to the capability of the courses to foster learner autonomy.

As demonstrated in Table 4, most of the participants agreed that the courses were aimed at promoting autonomous ESP learning introducing extra materials along with the prescribed instructional content (Students: $M=3.27, S D=1.35$; Instructors: $M=$ $3.22, S D=1.08$ ). The use of the other techniques was not confirmed by the majority of the respondents.

\section{Comparative analysis of the students' and instructors' attitudes}

To address the last research question, a statistical comparison was drawn between the students and instructors' attitudes toward the ESP course. As the initial stage, the sum of the scales chosen by every participant to rate the items representing every particular domain was estimated an entitled Attitude Score. Table 5 shows the descriptive statistics of the instructors' and students' attitude scores in terms of the four course-related domains of the study.

As depicted in Table 5, the students' attitude toward the content authenticity $(M=$ 23.03, $S D=6.49)$ was a little more positive compared to the instructors $(M=20.46$, $S D=4.36)$. On the other hand, the instructors' attitude toward the items referring to the satisfaction of the target situation needs $(M=67.91, S D=11.04)$ was more positive compared to that of the student participants $(M=62.52, S D=12.59)$. Nonetheless, the instructors' and students attitudes toward the satisfaction of the learning needs satisfaction and content authenticity seem to be quite similar.

Assuming that the instructors' and students' overall perception of the courses is a function of their attitudes toward the four course-related domains, a one-way multivariate analysis of variance (MANOVA) was performed to examine the significance of the between-group differences. In advance of running MANOVA, however, the underlying assumptions required to report valid results (i.e., multivariate normality, no multicollinearity, homogeneity of variances) were checked and no violation was found. The MANOVA results are displayed in Table 6.

According to the results in Table 6, a significant difference was found between the instructors' and students' attitudes based on a linear combination of the four courserelated domains (Wilk's $\Lambda=.048, F(4,845)=4170.853, p<.001$, multivariate $\eta^{2}=.952$ ). 


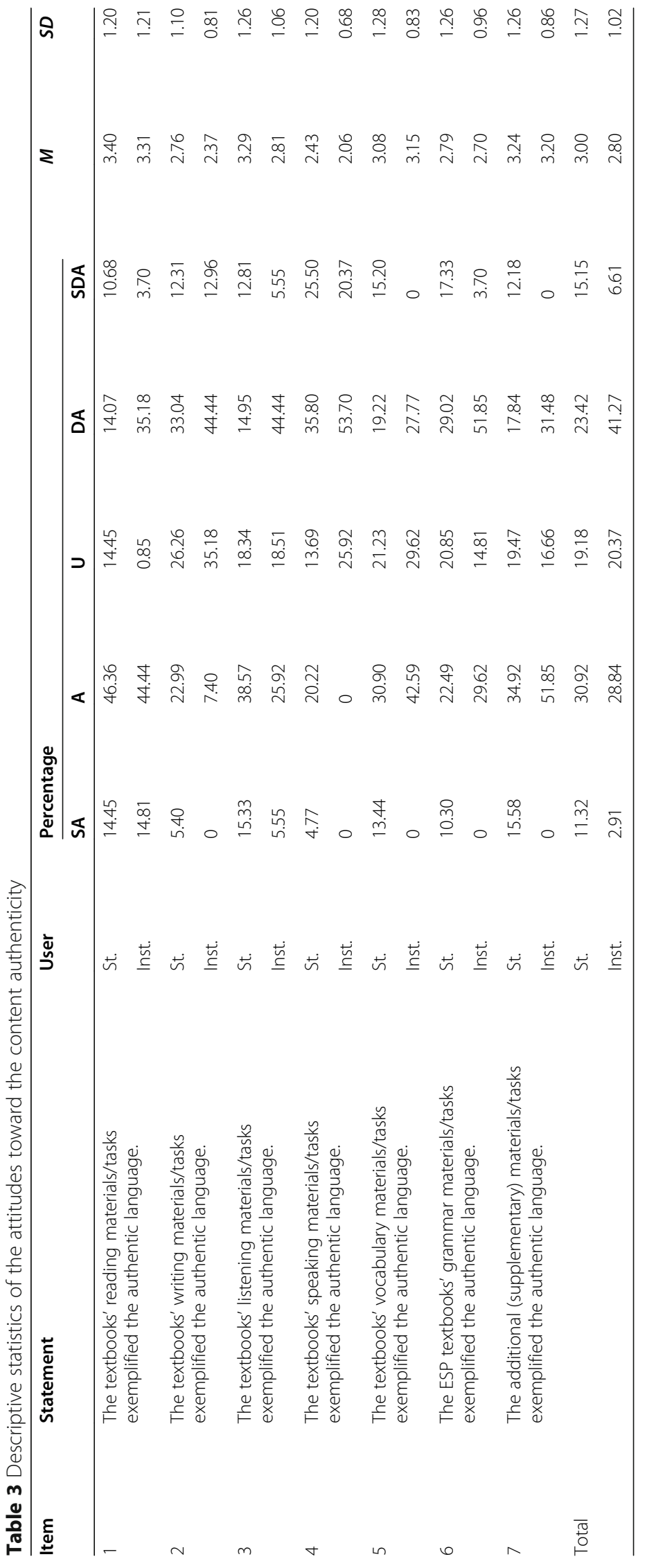




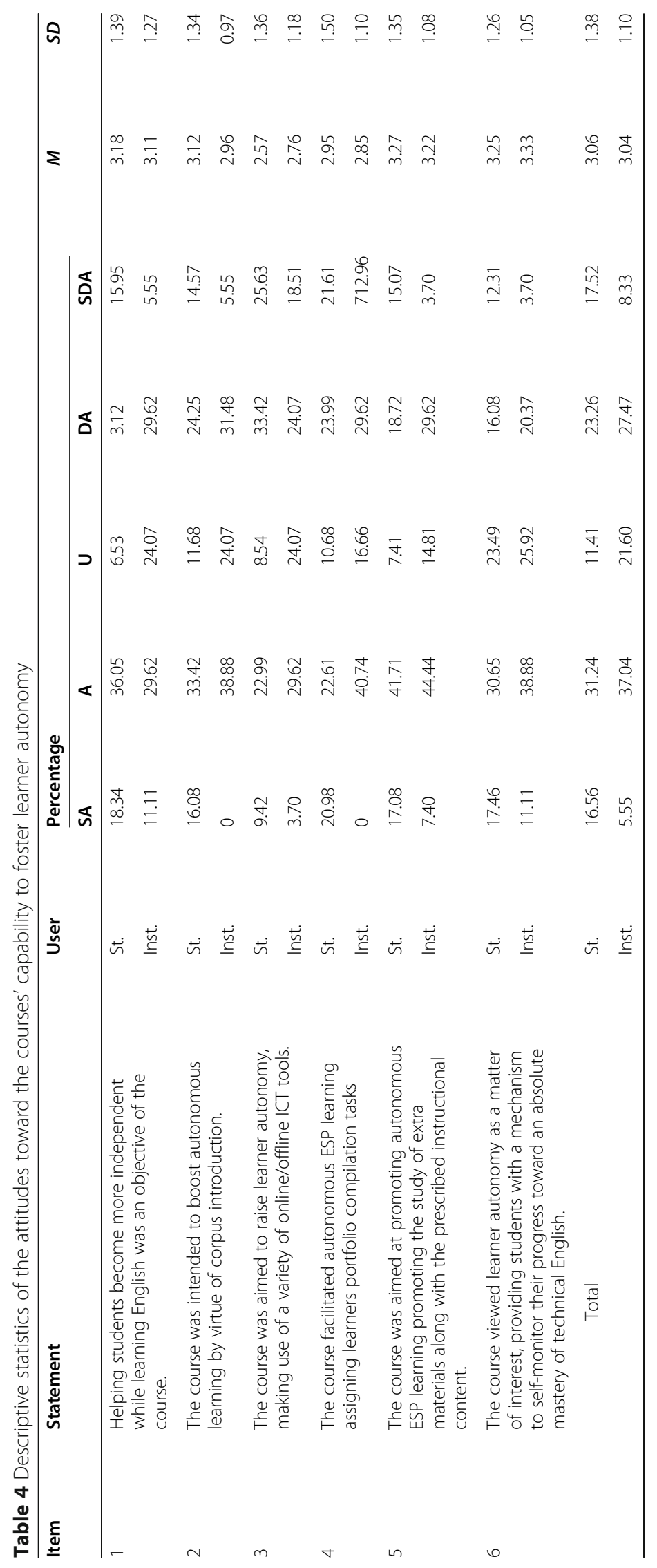


Table 5 Descriptive Statistics of the Attitude Scores Based on Different Course-Related Domains

\begin{tabular}{lllllll}
\hline Domain & User & N & Min & Max & Mean & SD \\
\hline Content Authenticity & St. & 796 & 14 & 37 & 23.03 & 6.49 \\
& Inst. & 54 & 12 & 30 & 20.46 & 4.36 \\
Target Needs Satisfaction & St. & 796 & 41 & 88 & 62.52 & 12.59 \\
& Inst. & 54 & 45 & 89 & 67.91 & 11.04 \\
Learning Needs Satisfaction & St. & 796 & 26 & 58 & 48.06 & 7.17 \\
& Inst. & 54 & 30 & 64 & 47.15 & 8.13 \\
Learner Autonomy & St. & 796 & 8 & 27 & 18.91 & 5.02 \\
& Inst. & 54 & 9 & 25 & 18.24 & 4.09 \\
\hline
\end{tabular}

The results revealed that approximately $95 \%$ of the difference in the instructors' and students' attitude toward the course could be attributed to the differences between these four domains.

To determine the domains that caused the significant difference between the users' attitude, test of between-subjects effects was performed. The results are displayed in Table 7.

As the results in Table 7 display, the significant difference between the two groups of participants was caused by the domains representing the content authenticity $(F(1$, $\left.848)=8.215, p<.0125, \eta^{2}=.010\right)$ and the satisfaction of the target situation needs $(F(1$, $\left.848)=9.389, p<.0125, \eta^{2}=.011\right)$. The specified level of significance (.05) was modified being divided by the number of dependent variables (4) to eliminate the possibility of the error caused as a result of running multiple ANOVAs.

\section{Discussion}

\section{Needs satisfaction}

The present study sought to evaluate the pedagogical worth of Iranian tertiary level ESP courses designed for Iranian students of engineering. To this end, the voice of ESP instructors and engineering students was relied upon to gauge the extent to which the courses has the potential to meet the real needs of students. Along with exploring the success of the courses in satisfying the learner needs, the evaluative framework of the study entailed an investigation into the authenticity of the instructional content and the capability of the courses to promote autonomous learning.

Based on the results drawn from descriptive analysis of the survey data, the overall satisfaction of the target situation needs was contradicted by the majority of the student participants. The item analysis results revealed that such general disagreement was mainly rooted in the students' negative attitude toward the satisfaction of the target needs relevant to writing and speaking skills. This finding seems to be in harmony with the findings of a number of previous studies (e.g., Mahdavi Zafarghandi et al., 2014;

Table 6 Results of MANOVA on the four attitudinal domains

\begin{tabular}{lllllll}
\hline Effect & Wilks' Lambda Value & $\mathbf{F}$ & Hypothesis df & Error df & Sig. & Partial Eta Squared \\
\hline Intercept & .048 & 4170.853 & 4 & 845 & .000 & .952 \\
User & .976 & 5.242 & 4 & 845 & .000 & .024 \\
\hline
\end{tabular}


Table 7 Results of between-subjects tests on the four attitudinal domains

\begin{tabular}{lllllll}
\hline Domain & $\begin{array}{l}\text { Type III Sum } \\
\text { of Squares }\end{array}$ & df & Mean Square & F & Sig. & $\begin{array}{l}\text { Partial } \\
\text { Eta Squared }\end{array}$ \\
\hline Content Authenticity & 333.928 & 1 & 333.928 & 8.215 & .004 & .010 \\
Learning Needs Satisfaction & 22.535 & 1 & 22.535 & .913 & .339 & .001 \\
Target Needs Satisfaction & 1466.995 & 1 & 1466.995 & 9.389 & .002 & .011 \\
Learner Autonomy & 42.540 & 1 & 42.540 & .783 & .376 & .001 \\
\hline
\end{tabular}

Zand-Moghadam et al., 2018) reflecting the failure of Iranian ESP courses to effectively promote productive skills.

In spite of the negative attitudes to the satisfaction of the needs related to productive language learning skills, the fulfillment of the needs relevant to receptive language learning skills (i.e., reading and listening) were found to be in a satisfactory situation. The success of Iranian ESP courses in satisfying reading comprehension needs, as evidenced by the current study and a substantial number of the previous studies (e.g., Alavi, Kaivanpanah, \& Taase, 2017; Mahdavi Zafarghandi et al., 2014), may be attributed in part to the empirically-evidenced significance of such need for Iranian tertiary level students (Alavi et al., 2017; Atai \& Nazari, 2011; Atai \& Shoja, 2011; Mazdayasna \& Tahririan, 2008; Soodmand Afshar \& Movassagh, 2016; Zand-Moghadam et al., 2018).

The findings concerning the reading needs, however, seem to bear no resemblance to what has been previously found by Alavi et al. (2017) that EAP classes do not effectively represent reading comprehension needs of undergraduate students. One reason behind the discrepancy between the two studies may be the methodological differences between them. Unlike the current study which took advantage of a structured questionnaire to survey the courses' stakeholders about the satisfaction of different ESP needs, the results of Alavi et al. (2017) study were drawn based on a classroom observation. Additionally, the differences in the reading needs of concern to the two studies may account for the discrepancy in the results.

As another finding, the courses were found to hardly meet the need for an effective communication in discipline-specific contexts and progressing in post-graduate education. The incapability of ESP courses to realize academic and occupational ESP learning objectives of Iranian tertiary level students lends support to the conclusion made by Mahdavi Zafarghandi et al. (2014) that "the courses are inadequate to prepare the students to practically utilize their language capabilities to succeed in their academic or occupational outlook" (p. 14).

Based on the results, the participants mostly confirmed the fulfillment of the vocabulary, and grammar needs throughout the ESP courses. The satisfaction of the needs relevant to language learning sub-skills (i.e., vocabulary and grammar), as revealed in the current study, has been previously validated by Zand-Moghadam et al. (2018) who investigated the fulfillment of the EAP needs of Humanities and Social Sciences learners and came to a conclusion that Iranian ESP courses are capable of meeting the grammar and vocabulary needs, from the students' perspectives.

The participants' overall attitudes toward the satisfaction of the learning needs bore a striking resemblance to their general perception of the target needs. In other words, the majority of the participants either contradicted or expressed uncertainty toward 
most of the needs referring to the ESP learning indices. Notwithstanding the negative attitudes toward the overall satisfaction of the learning needs, the satisfaction of the needs referring to the assessment system, type of tasks/activities, teacher expertise, scaffolding policy, place of the courses in the curriculum, and training hours were agreed by the participants to a certain extent.

The results drawn from a careful item analysis revealed that the educational facilities and the monitoring system were presumed by the participants to be in contradiction with their respective needs to a large extent. The mismatch between the educational facilities and the students' real needs lies in the absence of modern educational tools (e.g., smart boards) which could facilitate access to online learning resources. Concerning the monitoring system, the student participants mostly denied that there is an active type of monitoring which allows them to frequently ask for help and advice.

\section{Content authenticity}

The results relevant to the content authenticity of the courses testified to the students' overall disagreement in this regard. The follow up analysis (item analysis) results revealed that such overall disagreement was rooted in the students' dissatisfaction with the authenticity of the speaking, writing, vocabulary, and grammar materials/tasks used in the prescribed ESP textbooks. Compared with the student participants, the instructors' attitude was much more negative in terms of content authenticity. To this group of participants, with the exclusion of the textbooks' reading materials and the instructor-developed supplementary tasks/materials, none of the tasks and materials used throughout the courses could satisfy the learner need for accessing an authentic and real-nature ESP instructional content. The overall disagreement of the instructor participants with the inclusion of authentic tasks and materials in the discipline-specific textbooks sounds quite similar to the conclusion made by Zohoorian, Baghban, and Pandian (2011) that Iranian ESP textbooks are designed without adopting an authentic approach to materials development.

Despite the negative attitudes toward the overall content authenticity, the authenticity of the textbooks' reading materials/tasks were presumed to be satisfactory by the majority of the students and instructors. Although ESP textbooks evaluation has always been an important area of research, the issue of authenticity seems to be rarely explored as an independent subject of inquiry. Nevertheless, the authenticity of the textbook-derived reading materials are comparable to the findings of Khoshsima and Khosravani (2014) who explored the authenticity of ESP as an evaluative index of content appropriateness and concluded that the reading materials were perceived as authentic to some or a great extent.

In addition to the reading materials/tasks, the authenticity of the instructor-devised tasks/materials appealed to the majority of the student and instructor participants. This finding makes sense simply because these sorts of materials are basically developed based on the latest instances of language use in real situation with the purpose of compensating for the lack of realistic language use.

\section{Learner autonomy enhancement}

According to the results, a remarkable proportion of each participant groups either disagreed or expressed uncertainty about the use of techniques and strategies playing a 
central role in the cultivation of learner autonomy in ESP classrooms. The only policy its implementation was widely agreed by both the instructor and student participants was introducing extra materials along with the prescribed instructional content. The courses, however, failed to promote the other sorts of techniques such as providing learners with a self-monitoring mechanism, assigning them portfolio compilation tasks, making use of offline/online ICT tools as a means of internet-aided communication with native speakers, and instructing learners how to access and use discipline-specific ESP corpora.

In spite of the clear consensus between the two participant groups on the issues relevant to learner autonomy, the emphasis put by the courses on promoting autonomous learning was found to be an area of disagreement between them. Unlike the instructors who mostly contradicted or doubted that the ESP courses are intended to put a due emphasis on raising independent learning among ESP learners, the majority of the student participants confirmed that helping students become more independent while learning English is one major objective of the courses. Although in theory, learner autonomy is found to be closely linked to adult education in general and formal language teaching in particular (Karastateva, Makrieva, \& Krasteva, 2010), the study of learner autonomy as a key component in evaluation of ESP courses has received scant attention. Such paucity of relevant empirical evidence, therefore, hindered the exploration of the meaningfulness of the results drawn from the current study.

\section{Differences in the students' and instructors' viewpoints}

Based on the results gained from running MANOVA, a significant difference was found between the two participant groups in terms of their overall attitude to the courses under investigation. The post-hoc analysis results revealed that such difference is yielded by the differing attitudes toward the satisfaction of the target needs and the authenticity of the instructional content.

The difference in attitudes toward the courses' content authenticity could regard as an implicit support to the results drawn from Abbasian and Mahdavi's (2011) study showing that teachers and learners, as major beneficiaries of ESP courses, hold different views toward the authenticity of Iranian ESP textbooks. Such different views seem quite logical, inasmuch as the students' realization of the type of language they are to deal with throughout their working/learning life is supposed to be very limited compared to that of the instructor ones. Similarly, the ESP instructors' far better understanding of an ideal ESP course, and the requirements thereof, may account for the significantly different attitudes of the instructors and students to the target needs satisfaction.

\section{Conclusions}

In sum, the scrutiny of the attitudes expressed by the participants showed a reckless disregard for the needs relevant to receptive skills. The courses, however, were found to be capable to meet the needs related to vocabulary learning and receptive skills. In addition, although capable of meeting a variety of learning needs such as making use of contentrelevant tasks and a combination of peer and teacher scaffolding, the courses seemed to hardly have the potential to fulfill the need for benefiting from an active type of assessment and modern educational facilities. Relying upon the participants' dissenting voices, it 
was also concluded that despite the latest endeavors to develop context-appropriate localized materials specific to Iranian students of engineering, the ESP courses still lack content authenticity. Furthermore, the failure of the courses under investigation to make use of autonomy enhancement techniques and strategies was proved to be problematic.

This study, and the results thereof, may not necessarily yield an immediate change in ESP pedagogy intended for Iranian engineering students. Nonetheless, it is likely to build up the willingness, tendency, and desire to bridge the gap between the existing ESP practices and their ideal state. In simpler terms, the findings may offer an analytical picture of the current technical English pedagogy in Iran whereby decision makers may acknowledge the need for adapting ESP teaching programs to suit the real needs of students. Undoubtedly, the process of modification and redesigning will be more likely to meet with success if the researchers motivated to expand upon the findings take account of other determining factors such as university type (i.e., private \& Public) and students' major. They could also incorporate a qualitative account into the evaluation, listening to the voices of a broader range of stakeholders (e.g., policy makers, material developers, and educational authorities) regarding the obstacles placed in the way of an effective technical teaching practice, and the tentative solutions to overcome them.

\section{Supplementary information}

Supplementary information accompanies this paper at https://doi.org/10.1186/s40862-021-00109-2.

Additional file 1.

\section{Abbreviations}

ANOVA: Analysis of Variance; EAP: English for Academic Purposes; ESP: English for Specific Purposes; ICT: Information and Communication Technology; MANOVA: Multivariate Analysis of Variance; SPSS: Statistical Pack for Social Sciences

\section{Acknowledgements}

We would like to appreciate two anonymous reviewers of the study as well as the participant of the study.

\section{Authors' contributions}

The lead author conducted the interviews. The second and third authors codified and analyzed the data. All authors are responsible for all parts of the paper. The author(s) read and approved the final manuscript.

Funding

No funding was available to the present study.

\section{Availability of data and materials}

The data will be available upon requesting.

Competing interests

The authors declare that they have no competing interests.

\section{Author details}

${ }^{1}$ Department of Foreign Languages, Islamic Azad University, South Tehran Branch, Tehran, Iran. ${ }^{2}$ Associate Professor of Applied Linguistics, English Department, Faculty of Persian Literature and Foreign Languages, Islamic Azad University, South Tehran Branch, Tehran, Iran. ${ }^{3}$ Imam Ali University, Tehran, Iran.

Received: 4 July 2020 Accepted: 5 January 2021

Published online: 20 January 2021

References

Abbasian, G., \& Mahdavi, A. (2011). Four pairs of binoculars watching a single prey: Evaluation of Iranian ESP textbooks: (teachers vs. students). Journal of English Studies, 1(3), 51-66.

Alavi, S. M., Kaivanpanah, S., \& Taase, Y. (2017). A needs-based evaluation of EAP syllabuses. Iranian Journal of English for Academic Purposes, 6(1), 1-16.

Aliakbari, M., \& Boghayeri, M. (2014). A needs analysis approach to ESP design in Iranian context. Procedia-Social and Behavioral Sciences, 98, 175-181.

Altmişdört, G. (2017). A study on students' and teachers' needs and expectations in English for specific purposes programs. Science Journal of Turkish Military Academy, 27(1), 53-78. 
Amirian, Z., \& Tavakoli, M. (2009). Reassessing the ESP courses offered to engineering students in Iran. English for specific purposes world, 8(23), 1-13.

Atai, M. R., \& Nazari, O. (2011). Exploring reading comprehension needs of Iranian EAP students of health information management (HIM): A triangulated approach. System, 39, 30-43.

Atai, M. R., \& Shoja, L. (2011). A triangulated study of academic language needs of Iranian students of computer engineering: Are the courses on track? RELC Journal, 42(3), 305-323.

Danaye-Tous, M., \& Haghighi, S. (2014). Evaluation of ESP textbooks: Evidence from ESP textbook of computer engineering major, University of Guilan, Iran. International Journal of Research Studies in Lanquage Learning, 3(2), 55-68.

Dobrota, C. (2009). Learner autonomy in ESP adult courses. Diacronia, 24(2), 507-512.

Dudley-Evans, T., \& St. John, M. J. (1998). Developments in English for specific purposes: Amulti-disciplinary approach. Cambridge: Cambridge University Press.

Hatam, A. H., \& Shafiei, S. (2012). The evaluation of the effectiveness of ESP courses in enhancing technical translation proficiency: A case study of ESP course for mechanical engineering students. English Language Teaching, 5(5), 68-78.

Hutchinson, T., \& Waters, A. (1987). English for specific purposes: A learning-centered approach. Cambridge: Cambridge University Press.

Hüttner, J., Smit, U., \& Mehlmauer-Larcher, B. (2009). ESP teacher education at the interface of theory and practice: Introducing a model of mediated corpus-based genre analysis. System, 37, 99-109.

Iranmehr, A., Atai, M. R., \& Babaii, E. (2018). Evaluation of EAP programs in Iran: Document analysis and expert perspectives. Applied Research on English Lanquage, 7(2), 171-194.

Karastateva, V., Makrieva, I., \& Krasteva, M. (2010). Fostering autonomy in ESP. Scientific University of Rousse, 49(6.3), 136-140.

Khodi, A. (2015). From an appraisal of Iranian ESP courses to curriculum development. International Journal of Research in ELT, $3(2), 13-20$.

Khoshsima, H., \& Khosravani, M. (2014). ESP textbooks criteria: A case study of Iranian universities. International Journal on Studies in English Language and Literature, 2(7), 42-49.

Kiely, R., \& Rea-Dickins, P. (2005). Program evaluation in language education. Hampshire: Palgrave Macmillan.

Little, D. (2006). Learner autonomy: Drawing together the threads of self-assessment, goal-setting and reflection Retrieved 4 March 2009, from http:/www.ecml.at/mtp2/ELP_TT/ELP_TT_CDROM/DM_layout/00_10/06/06\%20Suppementary\%20text.pdf.

Mahdavi Zafarghandi, A. (2005). Failure of meeting EST objectives Paper presented at the first national ESP/EAP Conference, SAMT.

Mahdavi Zafarghandi, A., Khalili Sabet, M., \& Sharoudi Lomar, S. (2014). Developing an ESP needs profile of Iranian students of business administration. International Journal of Research Studies in Language Learning, 3(5), 3-18.

Malmir, A., \& Bagheri, M. (2019). Instructors and learners' attitudes about English for science and technology: Learning and target needs of mechanical engineering students. Iranian Journal of English for Academic Purposes, 8(1), 17-37.

Mashhadi Heidar, D., \& Abassy Delvand, S. (2015). A survey on the efficiency of ESP teachers in Iranian universities. International Journal of Foreign Language Teaching \& Research, 11, 59-63.

Mazdayasna, G., \& Tahririan, M. H. (2008). Developing a profile of the ESP needs of Iranian students: The case of students of nursing and midwifery. Journal of English for Academic Purposes, 7, 277-289.

McNamara, C. (2000). The field quide for nonprofit program design. Marketing and evaluation. Minneapolis: Authentic Consulting.

Moslemi, F., Moinzadeh, A. \& Dabaghi, A. (2011). ESP needs analysis of Iranian MA students: A case study of the University of Isfahan. English Language Teaching, 4(4), 121-129.

Mostafaei Alaei, M., \& Ershadi, A. R. (2017). ESP program in Iran: A stakeholderbased evaluation of the program's goal, methodology, and textbook. Issues in Language Teaching, 5(2), 279-306.

O'Leary, C. (2007). Supporting the development of autonomy in advanced foreign language learners on an institution-wide language programme. In K. Smith (Ed.), Higher education research network conference: Making links, sharing research, (pp. 51-64). Sheffield: Sheffield Hallam University.

Sherkatolabbasi, M., \& Mahdavi Zafarghandi, A. (2012). Evaluation of ESP teachers in different contexts of Iranian universities. International Journal of Applied Linguistics \& English Literature, 1, 198-205.

Soodmand Afshar, H., \& Movassagh, H. (2016). EAP education in Iran: Where does the problem lie? Where are we heading? English for Academic Purposes, 22, 132-151.

Stavropoulou, A., \& Stroubouki, T. (2014). Evaluation of educational programmes: The contribution of history to modern evaluation thinking. Health Science Journal, 8(2), 193-204

Tsou, W., \& Chen, F. (2014). ESP program evaluation framework: Description and application to a Taiwanese university ESP program. English for Specific Purposes, 33, 39-53.

Wang, V. C. X. (2009). Assessing and evaluating adult learning in career and technical education. USA: Zhejiang University Press.

Watanabe, Y., Norris, J. M., \& Gonzales, L. M. (2009). Identifying and responding to evaluation needs in college foreign language programs. In J. M. Norris, J. David, C. Siniscrope, \& Y. Watanabe (Eds.), Towards useful program evaluation in college foreign lanquage education, (pp. 5-56). Honolulu: University of Hawaii Press.

Weir, C., \& Roberts, J. (1994). Evaluation in ELT. Oxford: Blackwell.

Worthen, B. R., Sanders, J. R., \& Fitzpatrick, J. L. (2004). Program evaluation: Alternative approaches and practical guidelines. Boston: Allyn and Bacon.

Zand-Moghadam, M., Meihami, H., \& Ghiasvand, F. (2018). Exploring the English language needs of EAP students of humanities and social sciences in Iran: A triangulated approach. Issues in Language Teaching (ILT), 7(1), 135-164.

Zohoorian, Z., Baghban, V., \& Pandian, A. (2011). A review on the effectiveness of using authentic materials in ESP courses, English for Specific Purposes World, 31(10), 1-14.

\section{Publisher's Note}

Springer Nature remains neutral with regard to jurisdictional claims in published maps and institutional affiliations. 